\title{
Research Paper: Prestige and Dominance as Differential Correlates of Moral Foundations and Its Clinical Implications
}

Hamid Khanipour $^{1^{*}}$ (D), Mahsan Pourali², Mojgan Atar ${ }^{2}$ (i)

1. Institue of Educational, Psychological, and Social Research, Kharazmi University, Tehran, Iran.

2. Department of Psychology, Faculty of Psychology and Education, Kharazmi University, Tehran, Iran.

\begin{tabular}{|c|c|}
\hline $\begin{array}{l}\text { Use your device to scan } \\
\text { and read the article online }\end{array}$ & \\
\hline 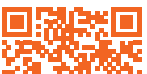 & $\begin{array}{l}\text { CFtat on: Khanipour, H., Pourali, M., \& Atar, M. (2021). Prestige and Dominance as Differential Correlates of Moral Founda- } \\
\text { tions and Its Clinical Implications. Journal of Practice in Clinical Psychology, 9(1), 1-8. https://doi.org/10.32598/jpcp.9.1.63.7 }\end{array}$ \\
\hline Chy & doi'https://doi.org/10.32598/jpcp.9.1.63.7 \\
\hline
\end{tabular}

\section{(c) (5)}

Article info:

Received: 19 Jun 2020

Accepted: 10 Aug 2020

Available Online: 01 Jan 2021

Keywords:

Social status, Morality, Social acceptance, Morals, Mental disorders

\section{ABSTRACT}

Objective: How people use social rank (dominance vs prestige) could explain different attitudes toward five moral foundations. This study aimed to investigate the differential relationships between prestige, dominance, and moral foundations.

Methods: This study was conducted on 150 participants who responded to the moral foundation questionnaire and dominance-prestige scale.

Results: Multiple regression analysis revealed that prestige was positively associated with four kinds of moral foundations (harm/care, reciprocity/fairness, loyalty/subversion, and purity/ sanctity), whereas dominance was negatively associated with harm/care, reciprocity/fairness, and progressivism. Prestige had a stronger association with moral foundations than dominance.

Conclusion: It seems that dominance as a social status seeking-strategy is against any moral foundation, but prestige could increase attention to moral foundations in decision making toward every life issue. 


\section{Highlights}

- Prestige is a better predictor of moral foundations than dominance.

\section{Plain Language Summary}

According to moral foundation theory, moral judgment is rooted in moral intuitions (including harm/care, fairness/ reciprocity, loyalty/subversion, authority/respect, purity/sanctity, and tendency to progressivism). Social status is considered something, which people eager to achieve in any society. Prestige and dominance have been delineated as two main social status-seeking styles. Prestige is a way of status achievement through developing moral virtues or gaining authentic and high-quality skills in a specific job, whereas dominance is regarded as an aggressive and intimidating strategy to achieve social status and rank. This study aimed to explore the relationship between social status seeking styles and moral foundations and explain clinical implications for those possible associations. A total of 150 participants were asked to respond to the moral foundation questionnaire and dominance-prestige scale. Findings revealed that prestige and dominance were associated with some of the moral foundations. Besides, if a deficiency in moral behavior or moral judgment is deemed as the manifestation of personality disorder or other mental disorders, it can be argued that prestige and dominance may be the right candidate for discriminating maladaptive personality patterns or some kind of mental disorders.

\section{Introduction}

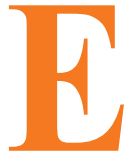

xperimental moral psychology revealed that ethical decision-making and conceptualization of moral foundations depends on cognitive and emotional process in agents and qualities of situations (Alfano, Loeb, \& Plakias, 2014). The moral foundation is an evolutionary theory about dimensions that people use for determining the morality aspects of a situation and making a moral judgment (Graham et al., 2011). According to moral foundation theory, people use five basic dimensions for defining morality: harm/ care, fairness/reciprocity, loyalty/subversion, authority/ respect, and purity/sanctity (Haidt, 2007). Every moral foundation relates to specific virtues. For example, the harm/care domain is related to attending to other people's life and autonomy, and the purity/sanctity domain is characterized by virtues like self-control, cleanliness, and spiritual purity (Haidt \& Joseph, 2004). These five moral concerns have been further categorized under two higher-order concerns: individualizing moral concerns (including harm/care and fairness/reciprocity) and binding moral concerns (including loyalty/subversion, authority/respect, and purity/sanctity) (Graham, Haidt, \& Nosek, 2009). Furthermore, the tendency to progressivism regarding one of the higher-order dimensions of moral foundations could also be determined by the proportional importance of individualizing to binding moral concerns (Graham et al., 2009). Progressivist people rely more on ethics of autonomy than ethics of divinity or the ethic of community in different cultures (Jensen, 1998).
People from different Socioeconomic Statuses (SES) and with different political orientations use different rules for moral judgment and have a different moral attitude towards social issues (Graham et al., 2009; Haidt \& Graham, 2007; van Leeuwen, Koenig, Graham, \& Park, 2014). For example, people with liberal political orientation more prioritize moral foundation related to harm/care and fairness/reciprocity, whereas people with conservative political orientation are more likely to endorse moral foundations related to loyalty/subversion, authority/respect, and purity/sanctity (Haidt \& Graham, 2007; Rai \& Fiske, 2011). People from low SES took a very broad attitude toward morality that relate morality to all personal life issues, whereas people from high SES would not moralize issues that are related to authority/ respect, loyalty/subversion, and purity/sanctity (Kraus, Piff, Mendoza-Denton, Rheinschmidt, \& Keltner, 2012; Monroe \& Plant, 2019; van Leeuwen et al., 2014; Piff, Stancato, Mendoza-Denton, \& Keltner, 2012). One group of psychological factors that could explain this kind of difference at the macro-level (i.e. SES or political orientation) is social seeking style.

Social status has been conceptualized as the extent of attention, regard, and prominence that each group ascribes to its members (Cheng, Tracy, \& Anderson, 2014). Dominance-prestige account argues that people use two distinct ways for attaining social status (Cheng, Tracy, Foulsham, Kingstone, \& Henrich, 2013). Although dominance has been conceptualized as a variation of power motive (Suessenbach, Loughnan, Schönbrodt, \& Moore, 2019; Suessenbach \& Moore, 2019) or social orientation 
towards inequality and hierarchy (Pratto, Sidanius, Stallworth, \& Malle, 1994), in a prestige-dominance account, dominance is regarded a forceful and intimidating strategy to gain social status and rank.

People who predominantly use dominance were more considered aggressive and narcissistic by their peer group (Redhead, Cheng, Driver, Foulsham, \& OGorman, 2019). Dominance is positively associated with dark personality traits like narcissism, psychopathy, and Machiavellianism (Cheng, Tracy, \& Henrich, 2010).

In contrast, prestige refers to status-seeking strategies that focus on respect, altruism, and developing authentic merits which used for rank attainment (Cheng, 2020; Cheng et al., 2013). In other words, people with prestige status-seeking style were more popular in groups. They would be recognized as skillful in a profession or possess real merit acknowledged by people in their social networks, and prestige is more effective on leveling social rank than dominance over time (Redhead et al., 2019).

It seems that these two strategies could differentially have associated with moral foundation domains. Prestige could be conceptualized as a moral interpersonal manner for status seeking. In contrast, dominance is related to antisocial interpersonal ways for status-seeking, ignoring other attitudes and feelings in life issues. It could be argued that dominance has negatively associated with the fairness/reciprocity dimension because people who rely on dominance are more prone to use injustice or aggressive strategies for status-seeking (Cheng et al., 2013; Redhead et al., 2019). Also, previous studies revealed that dominance is related to more aggressive behavior (Henrich \& Gil-White, 2001), and dominance motivated people more treat other people in an exploitive manner in their relationship (Cheng et al., 2010).

In contrast, previous studies revealed a positive association between prestige and valuing mutual respectful relationships (Redhead et al., 2019; Jonason, Wee, \& Li, 2015). Also, prestige-motivated people are more eager to be accepted by their peers, and moral behavior is one of main strategies they may use for status attainment (Bai, 2017; Halevy, Chou, Cohen, \& Livingston, 2012). The differential relationships between specific emotions like anger, contempt, and guilt with different moral foundations have been reported in previous studies (Horberg, Oveis, Keltner, \& Cohen, 2009; Steiger \& Reyna, 2017). These studies indirectly suggest that people with different traits and dispositions or motivations would make a different moral judgment. Although the role of trait emotions has been studied as predictors of moral foun- dations (Steiger \& Reyna, 2017), social status seeking styles have not been addressed as predictors of the moral foundation domain. The results of one study showed that prestige motive could positively and significantly predict higher moral concerns across all moral foundation, but dominance negatively associated with harm/care and fairness/reciprocity dimension and positively associated with loyalty/subversion, authority/respect, and purity/ sanctity dimension (Suessenbach et al., 2019). Investigating the links between prestige and dominance with domains of moral foundations could explain the diversity of moral concerns among people with different socio-cultural backgrounds. Furthermore, previous studies showed that people who rely on dominance compared with people who rely on prestige had lower self-esteem and lower well-being and more apply negative interpersonal behaviors (Cheng et al., 2014; Khanipour \& Fathi, 2020).

It could be argued that social status-seeking style could be related to the etiology of some personality disorders or some kind of psychopathology which showed in previous studies (Johnson, \& Carver, 2012; Johnson, Leedom, \& Muhtadie, 2012). By investigating the possible relationships between these social status seeking styles and moral foundations, we could find evidence for the role of these factors in some psychopathologies. This study aimed to examine how dominance and prestige could differentially be associated with five moral foundations and explain some clinical implications related to the role of prestige and dominance in the etiology of psychopathologies.

\section{Methods}

\section{The research design of this study is correlational}

\section{Study participants}

The study population was citizens of Tehran City, Iran, who voluntarily participated in this study. The study data were collected from January 2020 to April 2020. The inclusion criteria for enrolling participants to study included being 18-60 years old, being able to read and write and work by computer, and living in Iran. The sample size was calculated based on the 5 to 1 ratio of items to subjects which yielded 235 . However, at the final stage of data collection, some of the participants dropped out, and the final sample size was 150 . The study data were collected through a convenient sampling method, and finally, 150 people participated in the study (62 female and 88 male). All participants were informed of the study aims, and they completed informed consent. Some of the 
data were gathered through Google doc $(n=120)$ form of study instruments, and other data were obtained from participants in person $(n=35)$. The practical limitation of researching in the real world was the COVID-19 pandemic, and we had to use virtual and online data gathering methods, too. The study was conducted after getting codes of ethics (IR.KHU.REC.1399.003). The procedures followed were also in accordance with the ethical standards of the Helsinki Declaration of 1975, as revised in 2013. The participants were assured that their information would be kept confidential. They were informed that they could leave the research during the study whenever they wanted.

\section{Study measures}

Moral Foundation Questionnaire (MFQ): This questionnaire is designed to measure the degree of importance that is ascribed to five moral foundations. This questionnaire had six subscales: harm/care, fairness/ reciprocity, loyalty/subversion, authority/respect, purity/ sanctity, and progressivism index. This questionnaire consisted of two sections. The answer for part one was scored from 0 for "not at all relevant" to 5 for "extremely relevant," and part two answers was scored from 0 for "strongly disagree" and 5 for "strongly agree" (Graham et al., 2011). Each subscale score was calculated by adding related items together and then divided by 6 . Progressivism is an index in scoring MFQ, which is calculated through decreasing individualizing moral foundation from the binding moral foundation. A higher score in progressivism means getting a higher score in individualizing moral foundations (Graham et al., 2009). The Persian form of this questionnaire was used in this study (Nejat \& Hatami, 2019). The five-factor model of this questionnaire has been confirmed among Iranian university students, and its Cronbach alpha ranged between 0.66 and 0.074 for five subscales (Nejat \& Hatami, 2019).

Dominance-Prestige Scale (DPS): This scale was used to measure different social status seeking strategies. Prestige and dominance are psychological processes that individuals use to gain social ranks in social groups. People who use the dominance strategy gain social rank through force, fear, and threat; however, prestige strategy users gain respect by benefiting others and using honorable strategies (Cheng et al., 2013). This scale consisted of 17 items related to examples of the prestigious or dominance-based way for status seeking. It is scored on a Likert-type scale, and participants were asked to rate themselves in each item from " $0=$ not at all" to " $7=$ always". Previous studied reveal that the reliabilities of the prestige and dominance subscale were 0.83 and 0.85 , respectively (Cheng et al., 2010). Also, the Persian version of this scale which was used in this study was confirmed the two-factor model of the original scale, and its Cronbach alpha values were 0.81 for prestige and 0.73 for dominance among faculty members of a university in Tehran (Khanipour \& Fathi, 2020). In this study, the internal consistency for dominance and prestige were 0.60 and 0.80 .

\section{Results}

Most participants had a BA (78 people) degree; 44 people had a MA degree; 21 people had a diploma, and 7 individuals had a PhD. Also, 39 participants worked in the public sector, 73 worked in the private sector, and 35 were college students. They classified themselves in 4 different socioeconomic levels: 4 in the lower class, 44 in the lower-middle class, 96 in the upper-middle class, and 6 in the upper class. The results of descriptive statistics for all variables are presented in Table 1.

The results of conducting the Independent $t$ test between male and female showed no differences in study variables $(\mathrm{P}>0.05)$, but the results of multivariate analysis of variance showed that the differences between four socioeconomic class were significant (Wilks's Lambda $=0.73$; $\mathrm{F}=2.14 ; \mathrm{P}<0.05)$. Specifically, the results of post hoc analysis showed significant differences for dominance (mean differences $=9.48 ; \mathrm{P}=0.017)$, harm/care $(-4.46$; $\mathrm{P}=0.023)$, fairness/reciprocity $(-4.43 ; \mathrm{P}=0.015)$ between high socioeconomic class and middle socioeconomic class. According to the findings, people from high socioeconomic class scored higher in dominance and lower in harm/care and fairness/reciprocity compared with people in the middle socioeconomic class.

The correlation between prestige, dominance, and moral foundations is presented in Table 2. To examine the differential relationships between dominance and prestige with five domains of moral foundation, we considered prestige and dominance the independent variables separately, and each of the five domains as the dependent variable and then examined them by multiple regression analysis.

The result of the multiple regression analysis (Table 3 ) on the first foundation (harm/care) revealed that both dominance $(\mathrm{b}=-0.216 ; \mathrm{t}=-2.72 ; \mathrm{P}<0.001)$ and prestige $(b=0.250 ; t=3.15 ; \mathrm{P}<0.001)$ significantly predicted harm/ care foundation variance $(\mathrm{F}=7.64 ; \mathrm{P}<0.001)$. About the second variable, the result of regression analysis indicated that prestige $(\mathrm{b}=0.360 ; \mathrm{t}=3.92 ; \mathrm{P}<0.001)$ positively and dominance $(\mathrm{b}=-0.227 ; \mathrm{t}=-2.91 ; \mathrm{P}<0.001)$ negatively predicted fairness/loyalty $(\mathrm{F}=10.54 ; \mathrm{P}<0.001)$. About the 
Table 1. The mean and standard deviation for study variables

\begin{tabular}{cc}
\hline Variables & Mean \pm SD \\
\hline Dominance & $30.2 \pm 7.53$ \\
\hline Prestige & $45.76 \pm 7.63$ \\
\hline Harm/Care & $23.77 \pm 3.67$ \\
\hline Fairness/Reciprocity & $24.38 \pm 3.48$ \\
\hline Loyalty/Subversion & $21.56 \pm 3.99$ \\
\hline Authority/Respect & $18.68 \pm 4.36$ \\
\hline Purity/Sanctity & $20.78 \pm 4.49$ \\
\hline Progressivism & $3.71 \pm 3.13$ \\
\hline
\end{tabular}

Table 2. Zero-order correlation between prestige, dominance, and moral foundations

\begin{tabular}{ccccccc}
\hline Variables & Harm/Care & Fairness/Reciprocity & Loyalty/Subversion & Authority/Respect & Purity/Sanctity & Progressivism \\
\hline Dominance & $-0.181^{*}$ & $0.184^{*}$ & -0.001 & 0.103 & -0.046 & -0.176 \\
Prestige & $0.220^{* *}$ & $0.274^{* *}$ & $0.243^{* *}$ & 0.071 & $0.294^{* *}$ & -0.96 \\
\hline
\end{tabular}

${ }^{*} \mathrm{P}<0.05 ;{ }^{* *} \mathrm{P}<0.001$.

with little effect predict progressivism and the link between prestige and progressivism was not significant.

$\mathrm{P}<0.001)$ positively predicted $5 \%$ of loyalty/subversion variance $(\mathrm{F}=9.28 ; \mathrm{P}=0.003)$. About the fourth moral foundation, neither prestige nor dominance predicted authority/respect. Although purity/sanctity moral foundation has not predicted by dominance, prestige $(b=0.294$; $\mathrm{t}=3.73 ; \mathrm{P}<0.001)$ predicted $8 \%$ of the variation of this foundation $(\mathrm{F}=13.97 ; \mathrm{P}<0.001)$. In the final regression analysis, only dominance $(b=-.176 ; t=-2.17 ; \mathrm{P}<0.001)$

\section{Discussion}

The findings of this study demonstrated that prestige and dominance could differentially predict moral foundations. The results of this study indicated that prestige has positively associated with moral foundations related to

Table 3. Hierarchical regressions of morality foundation based on the prestige and dominance

\begin{tabular}{|c|c|c|c|c|c|c|c|c|c|c|}
\hline \multirow{3}{*}{ Criterion Variable } & \multicolumn{10}{|c|}{ Predictor Variable } \\
\hline & \multicolumn{5}{|c|}{ Dominance } & \multicolumn{5}{|c|}{ Prestige } \\
\hline & B & Beta & $\mathbf{R}^{2}$ & $\mathbf{t}$ & Sig. & B & Beta & $\mathbf{R}^{2}$ & $\mathbf{t}$ & Sig. \\
\hline Harm/Care & -0.105 & -0.216 & 0.048 & -2.72 & 0.007 & 0.120 & 0.250 & 0.082 & 3.15 & 0.002 \\
\hline Fairness/Reciprocity & -0.0105 & -0.227 & 0.050 & -2.91 & 0.004 & 0.140 & 0.360 & 0.075 & 3.92 & 0.001 \\
\hline Loyalty/Subversion & - & - & - & - & - & 0.127 & 0.243 & 0.059 & 3.04 & 0.003 \\
\hline Authority/Respect & - & - & - & - & - & - & - & - & & \\
\hline Purity/Sanctity & - & - & - & - & - & 0.173 & 0.294 & 0.086 & 3.73 & 0.001 \\
\hline Progressivism & -0.203 & -0.176 & 0.031 & -2.17 & 0.031 & - & - & - & - & - \\
\hline
\end{tabular}


care, fairness, loyalty, and sanctity. Findings also demonstrated that dominance was negatively associated with two moral foundations of care and fairness. Furthermore, the multiple regression analysis showed that moral foundations were predicted more by prestige than dominance.

The association between prestige and moral foundations is partially consistent with a previous study result (Suessenbach et al., 2019). Given that prestige is achieved through social desirability and popularity among group members, it is reasonable to see the strong role of prestige as a better predictor of higher concerns for morality. It seems that morality and prestige have a bidirectional relationship. In other words, prestige could be regarded as a cause and consequence of higher concerns for morality because prestige acts as a way to signaling morality (Bai, 2017). In an evolutionary account, morality is defined as a kind of merit that is ascribed to a person who acts consistently with the moral standards of his/her tribe (Joyce, 2007). This definition of morality is so similar to the conceptual definition of prestige. Also, people with prestige could use more persuasive way to gain status (Cheng et al., 2014), and a higher level of status is conversely related to body hormones related to aggression (Johnson, Burk, \& Kirkpatrick, 2007). The only moral foundation which was not associated with prestige was the authority/respect domain which was inconsistent with previous study findings (Suessenbach et al., 2019). It could be argued that moral foundation related to authority is not mirthful for this study's participants and is not considered a valuable moral attitude for people with a higher level of prestige. In other words, the prestige-motivated people less moralized authority as a morality concern. A previous study also showed that this moral concern (authority/ respect) is more related to conservative political ideology than liberal political ideology (Graham et al., 2009).

Another finding of this study demonstrated that dominance was not related to the moral foundations pertaining to authority, loyalty, and sanctity, whereas moral foundations related to care and reciprocity were negatively predicted by dominance. These results were inconsistent with previous study results that demonstrated a positive association between dominance desire and these moral foundations (Suessenbach et al., 2019). It could be argued that the desire for dominance which is considered the manifestation of power motive or as a facet of social dominance orientation (Pratto et al., 1994), differs from dominance as a way to reach and stabilize social status in a group. Although the dominance desire predisposes people to prioritize social hierarchy and increase groupbased morality, the dominance to get the social status (Cheng et al., 2013) is related to dark personality traits like Machiavellianism and psychopathy (Cheng et al., 2010). As our study revealed, it leads to less attention to moral foundations, even for binding moral concerns.

Findings related to the weak and negative relationship between dominance and progressivism and the non-significant relationship between prestige and progressivism are partially consistent with the prediction of this current study. People with dominance have less concern toward basic individualizing moral foundations (Suessenbach et al., 2019), explaining the reverse association between dominance and progressivism. The lack of association between prestige and progressivism may be due to that prestige-motivated people have deep concerns for almost all of the five moral foundations, which is different from progressivism and are conceptualized as a deep concern for individualizing moral concerns and less concern for binding moral concerns (Graham et al., 2009).

Overall, the role of prestige is stronger than dominance in predicting moral foundations. This result may be due to the role of morality as a way for gaining status among prestige-motivated people (Bai, 2017), whereas force and coercion act this function for reaching status among dominance-motivated persons. Also, maybe prestige as a psychological mechanism has been evolutionarily developed later than dominance (Henrich \& Gil-White, 2001), and prestige is more related to moralizing life issues.

The results of this study could have some clinical implications. Lay people consider personality disorders or some kind of other mental disorder as immorality. The findings of this study showed that dominance and prestige could differentially be related to set priorities for different moral foundations. Therefore, it could be argued that prestige and dominance may be the right candidates for discriminating maladaptive personality disorders or mental disorders. This study supports some previous studies that demonstrated the links between dominance and some kinds of mental disorders (Johnson, \& Carver, 2012; Johnson et al., 2012). People with dominance style had more difficulty in processing emotions related to social dominance that could express themselves in symptoms like mania, narcissism, and externalizing disorders. Anxiety and depression may also be related to perceived subordination or unsatisfied dominance needs (Sloman, $\&$ Gilbert, 2000). From the positive relationship between prestige and most of the moral foundations, we could infer that people who resolve issues related to the social hierarchy by cultivating prestige had fewer problems in adaptation, even in countries with a high dominancebased culture like Iran (Abramson, \& Inglehart, 1994). Besides, achieving social status is one of the basic needs 
in human beings, and many mental disorders are fundamentally related to how this need is satisfied (Cheng et al., 2014). Some negative emotions like shame or anger are related to failure to reach social status, and psychotherapy systems try to help people adjust to these kinds of emotions (Sloman, \& Gilbert, 2000). Exploring the developmental basis of prestige and dominance could help achieve a better understanding of some mental disorders and develop more efficacious psychotherapy.

\section{Conclusion}

Nevertheless, this study has some limitations that should be considered. First, the assessment of prestige and dominance was based on self-report. Given that these two features are so related to social judgment, it is better to apply peer-rated measures for assessing them in future studies. Second, the role of other known correlates in moral foundations such as socioeconomic status, political ideology, and religious orientation were not addressed in this study. It will be interesting to test the role of prestige and dominance in a more controlled condition and account for these social and political factors.

\section{Ethical Considerations}

\section{Compliance with ethical guidelines}

The study was conducted after getting codes of ethics (IR.KHU.REC.1399.003). The procedures followed were also in accordance with the ethical standards of the Helsinki Declaration of 1975, as revised in 2013. The participants were assured that their information would be kept confidential. They were informed that they could leave the research during the study whenever they wanted.

\section{Funding}

This study was funded by Vice-Chancellor for Research and Technology of Kharazmi University.

\section{Authors' contributions}

Conceptualization, Investigation, Data analysis, and Writing - original draft: Hamid Khanipour; Data analysis and Data collection: Mahsan Pourali and Mojgan Atar.

\section{Conflict of interest}

The authors declared no conflict of interest.

\section{References}

Abramson, P. R., \& Inglehart, R. (1994). Education, security, and postmaterialism: A comment on duch and Taylor's "Postmaterialism and the Economic Condition". American Journal of Political Science, 38(3), 797-814. [DOI:10.2307/2111607] [DOI:10.2307/2111607]

Alfano, M., Loeb, D., \& Plakias, A. (2014). Experimental moral philosophy. Retrieved from https://plato.stanford.edu/ entries/experimental-moral/\#: :text=Experimental $\% 20$ moral\%20philosophy \%20is\%20the, undermine $\% 2 \mathrm{C} \% 20$ or $\% 20$ revise\%20philosophical\%20theories.

Bai, F. (2017). Beyond Dominance and competence: A moral virtue theory of status attainment. Personality and Social Psychology Review, 21(3), 203-27.[DOI:10.1177/1088868316649297]] [PMID]

Cheng, J. T. (2020). Dominance, prestige, and the role of leveling in human social hierarchy and equality. Current Opinion in Psychology, 33, 238-44. [DOI:10.1016/j.copsyc.2019.10.004] [PMID]

Cheng, J. T., Tracy, J. L., \& Anderson, C. (2014). The psychology of social status. Springer: New York. [DOI:10.1007/978-1-49390867-7]

Cheng, J. T., Tracy, J. L., Foulsham, T., Kingstone, A., \& Henrich, J. (2013). Two ways to the top: Evidence that dominance and prestige are distinct yet viable avenues to social rank and influence. Journal of Personality and Social Psychology, 104(1), 103-12. [DOI:10.1037/a0030398] [PMID]

Cheng, J. T., Tracy, J. L., \& Henrich, J. (2010). Pride, personality, and the evolutionary foundations of human social status. Evolution and Human Behavior, 31(5), 334-47. [DOI:10.1016/j. evolhumbehav.2010.02.004]

Graham, J., Haidt, J., \& Nosek, B. A. (2009). Liberals and conservatives rely on different sets of moral foundations. Journal of Personality and Social Psychology, 96(5), 1029-46. [DOI:10.1037/ a0015141] [PMID]

Graham, J., Nosek, B. A., Haidt, J., Iyer, R., Koleva, S., \& Ditto, P. H. (2011). Mapping the moral domain. Journal of personality and social psychology, 101(2), 366-85. [DOI:10.1037/a0021847] [PMID] [PMCID]

Haidt, J. (2007). The new synthesis in moral psychology. Science, 316(5827), 998-1002. [DOI:10.1126/science.1137651] [PMID]

Haidt, J., \& Graham, J. (2007). When morality opposes justice: Conservatives have moral intuitions that liberals may not recognize. Social Justice Research, 20(1), 98-116. [DOI:10.1007/ s11211-007-0034-z]]

Haidt, J., \& Joseph, C. (2004). Intuitive ethics: How innately prepared intuitions generate culturally variable virtues. Daedalus, 133(4), 55-66. [DOI:10.1162/0011526042365555]

Halevy, N., Chou, E. Y., Cohen, T. R., \& Livingston, R. W. (2012) Status conferral in intergroup social dilemmas: Behavioral antecedents and consequences of prestige and dominance. Journal of Personality and Social Psychology, 102(2), 351-66. [DOI:10.1037/a0025515]] [PMID]

Henrich, J., \& Gil-White, F. J. (2001). The evolution of prestige: Freely conferred deference as a mechanism for enhancing the benefits of cultural transmission. Evolution and Human Behaviour, 22(3), 165-96. [DOI:10.1016/S1090-5138(00)00071-4] 
Horberg, E. J., Oveis, C., Keltner, D., \& Cohen, A. B. (2009). Disgust and the moralization of purity. Journal of Personality and Social Psychology, 97(6), 963-76. [DOI:10.1037/a0017423] [PMID]

Jensen, L. A. (1998). Moral divisions within countries between orthodoxy and progressivism: India and the United States. Journal for the Scientific Study of Religion, 37(1), 90-107. [DOI:10.2307/1388031]

Johnson, R. T., Burk, J. A., \& Kirkpatrick, L. A. (2007). Dominance and prestige as differential predictors of aggression and testosterone levels in men. Evolution and Human Behavior, 28(5), 345-51. [DOI:10.2307/1388031]

Jonason, P. K., Wee, S., \& Li, N. P. (2015). Competition, autonomy, and prestige: Mechanisms through which the Dark Triad predict job satisfaction. Personality and Individual Differences, 72, 112-6. [DOI:10.1016/j.paid.2014.08.026]

Johnson, S., \& Carver, C. (2012). The dominance behavioral system and manic temperament: Motivation for dominance, self-perceptions of power, and socially dominant behaviors. Journal of Affective Disorders, 142(1-3), 275-82. [DOI:10.1016/j. jad.2012.05.015]] [PMID] [PMCID]

Johnson, S., Leedom, L., \& Muhtadie, L. (2012). The dominance behavioral system and psychopathology: Evidence from selfreport, observational, and biological studies. Psychological bulletin, 138(4), 692-743. [DOI:10.1037/a0027503] [PMID] [PMCID]

Joyce, R. (2007). The evolution of morality. Cambridge: MIT Press. https:// books.google.com/books?id=3nk5Lq2hY9EC\&dq

Khanipour, H., \& Fathi, E. (2020). Organizational Support, Participation in Organizational Decision making, Organizational Politics, and Perceived Social Status among faculty members: the mediating effects of status seeking styles. Iranian Journal of Management Studies, 13(4), 623-44. [DOI:10.22059/ IJMS.2020.281430.673636]

Kraus, M. W., Piff, P. K., Mendoza-Denton, R., Rheinschmidt, M. L., \& Keltner, D. (2012). Social class, solipsism, and contextualism: how the rich are different from the poor. Psychological Review, 119(3), 546-72. [DOI:10.1037/a0028756] [PMID]

Monroe, A. E., \& Plant, E. A. (2019). The dark side of morality: Prioritizing sanctity over care motivates denial of mind and prejudice toward sexual outgroups. Journal of Experimental Psychology General. 148(2), 342-60. [DOI:10.1037/xge0000537] [PMID]

Nejat, P., \& Hatami, J. (2019). [Psychometric properties of the persian version of moral foundations questionnaire in three Iranian samples (Persian)]. Social Cognition, 8(1), 107-24. [DOI:10.30473/SC.2019.40617.2204]

Piff, P. K., Stancato, D. M., Côté, S., Mendoza-Denton, R., \& Keltner, D. (2012). Higher social class predicts increased unethical behavior. Proceedings of the National Academy of Sciences, 109(11), 4086-91. [DOI:10.1073/pnas.1118373109] [PMID] [PMCID]

Pratto, F., Sidanius, J., Stallworth, L. M., \& Malle, B. F. (1994). Social dominance orientation: A personality variable predicting social and political attitudes. Journal of Personality and Social Psychology, 67(4), 741-63. [DOI:10.1037/0022-3514.67.4.741]

Rai, T. S., \& Fiske, A. P. (2011). Moral psychology is relationship regulation: Moral motives for unity, hierarchy, equality, and proportionality. Psychological Review, 118(1), 57-75. [DOI:10.1037/a0021867] [PMID]
Redhead, D., Cheng, J. T., Driver, C., Foulsham, T., \& O'Gorman R. (2019). On the dynamics of social hierarchy: A longitudinal investigation of the rise and fall of prestige, dominance, and social rank in naturalistic task groups. Evolution and Human Behavior, 40(2), 222-34. [DOI:10.1016/j.evolhumbehav.2018.12.001]

Sloman, L., \& Gilbert, P. (2000). Subordination and defeat: An evolutionary approach to mood disorders and their therapy. New York: Routledge. https://books.google.com/ books?id=cbGPAgAAQBAJ\&dq

Steiger, R. L., \& Reyna, C. (2017). Trait contempt, anger, disgust, and moral foundation values. Personality and Individual Differences, 113, 125-35. [DOI:10.1016/j.paid.2017.02.071]

Suessenbach, F., Loughnan, S., Schönbrodt, F. D., \& Moore, A. B. (2019). The dominance, prestige, and leadership account of social power motives. European Journal of Personality, 33(1), 7-33. [DOI:10.1002/per.2184]

Suessenbach, F., \& Moore, A. B. (2019). Dominance desires predicting conspiracy beliefs and Trump support in the 2016 US Election. Motivation Science, 6(2), 171-6. [DOI:10.1037/ mot0000146]

Van Leeuwen, F., Koenig, B. L., Graham, J., \& Park, J. H. (2014). Moral concerns across the United States: Associations with life-history variables, pathogen prevalence, urbanization, cognitive ability, and social class. Evolution and Human Behavior, 35(6), 464-71. [DOI:10.1016/j.evolhumbehav.2014.06.005] 